\title{
Comparative Accuracy Assessment of Combined MODIS and NAAPS Aerosol Optical Depth with AERONET Data over North Africa
}

\author{
Clement 0. Akoshile1, Sarafadeen Shehu-Aladodo1,2* (D), Muawiya Sani², Jibril 0. Otu², \\ Benjamin T. Ajibola ${ }^{1}$
}

${ }^{1}$ Physics Department, University of Ilorin, Ilorin, Nigeria

${ }^{2}$ Centre for Atmospheric Research, NASRDA, Anyigba, Nigeria

Email: *aladodoshehu@gmail.com

How to cite this paper: Akoshile, C.O., Shehu-Aladodo, S., Sani, M., Otu, J.O. and Ajibola, B.T. (2019) Comparative Accuracy Assessment of Combined MODIS and NAAPS Aerosol Optical Depth with AERONET Data over North Africa. Atmospheric and Climate Sciences, 9, 398-420.

https://doi.org/10.4236/acs.2019.93028

Received: March 11, 2019

Accepted: July 15, 2019

Published: July 18, 2019

Copyright $\odot 2019$ by author(s) and Scientific Research Publishing Inc. This work is licensed under the Creative Commons Attribution International License (CC BY 4.0).

http://creativecommons.org/licenses/by/4.0/

(c) (i) Open Access

\begin{abstract}
Aerosol is one of the important geophysical parameters that determine the earth's radiation budget, energy balance and hydrological cycle. The "Deep Blue" Moderate Resolution Imaging Spectro-radiometer (MODIS) Aerosol Optical Depth (AOD) retrieval algorithm was designed to complement existing "Dark Target" Ocean and Land algorithms to be able to retrieve AOD over bright land surface. Using level $2 \mathrm{AOD}$ data from five Aerosol Robotic Network (AERONET) stations over the study location of North Africa $\left(0^{\circ} \mathrm{S}\right.$ $40^{\circ} \mathrm{N}, 30^{\circ} \mathrm{W}-60^{\circ} \mathrm{E}$ ), comparative accuracy assessments are made for combined MODIS AOD aboard Terra and Aqua satellites and US Navy Aerosol Analysis and Prediction System (NAAPS) forecast AOD data. The aerosol transport and vertical mixing over the region are investigated at different altitudes up to $3000 \mathrm{~m}$ above ground level using Hybrid Single Particle Lagrangian Integrated Trajectory (HYSPLIT). The MODIS validation result shows highest correlation in the Sub-Sahel (0.811) followed by Sahel (0.726) and then Sahara region (0.662). Furthermore, the combined retrieval algorithm of Terra and Aqua MODIS shows statistically significant discrepancies from AERONET AOD values in term of mean, $t$-test value, index of agreement and fractional error. The comparison of NAAPS predicted soil dust to AERONET AOD fared best in December to February (DJF) season for the Sahel region and June to August (JJA) season for the Sahara when the dust emission and transport are at the peak. However, median ratios of NAAPS to AERONET AOD indicated bias in some island sites in the Atlantic Ocean which may be due to the presence of sea salt over the site. The analysis carried out in this study reveals that both MODIS retrieval algorithm and NAAPS model could be improved by incorporating some local aerosol sources from the study area.
\end{abstract}




\section{Keywords}

Aerosol, Deep Blue, Dark Target, Algorithm, Validation

\section{Introduction}

One of the long observing space-borne instruments that acquire AOD is the MODerate resolution Imaging Spectro-radiometer (MODIS), which is a 36-band spectrometer covering land and ocean and widely used by researchers [1]. The combination of two instruments (radiometer) in flight aboard the two ships giving daily near-global observations, makes the MODIS sensors an enticing choice for such an aerosol dataset for researchers. The uncertainty is $\pm 0.05( \pm 0.15 \times$ AOD) over land and $\pm 0.03( \pm 0.05 \times \mathrm{AOD})$ over the ocean. The MODIS retrieval algorithm for AOD considers assumptions regarding surface reflectance, aerosol properties, meteorological conditions etc. [2]. Each one has a significant role it plays in AOD retrieval over different aerosol regions. Many studies have evaluated the satellite retrievals of aerosol products in many locations. Reference [3] evaluates the uncertainties of Collection 6 over Land and Water. Low and high biases are quite clear for fine and coarse mode aerosol particles over water. Uncertainties are also shown over coastal regions, where runoff and/or biological activities create issues for the surface boundary conditions.

The over-land problem, however, is much more complicated. The lower boundary condition for MODIS Dark Target Collection 5 is empirical and cannot cope with all land forms everywhere. The more complicated land surface also reduces the degrees of freedom in available microphysical models that can be utilized by the retrievals [4]. This is because aerosol retrieval is based on the comparison of the cloud-free radiation (both from land surface and atmospheric molecules) received by the instrument at Top of Atmosphere (TOA) with that of pre-computed ones using a radiative transfer model for the same geometry and atmospheric conditions. The radiation scattered by aerosol particles is in different directions with an angular distribution that depends on particle size, shape, and chemical composition, and any aerosol retrieval algorithm uses the angular dependence of the aerosol scattering [5]. The algorithm assumes that one fine dominated aerosol model and one coarse dominated aerosol model (each may be comprised of multiple lognormal modes) can be combined with proper weightings to represent the ambient aerosol properties over the target. Some assumptions have to be made in the retrieval since Earth's surface, molecular atmosphere and aerosols do not have entirely independent spectral signatures.

Aerosol optical depth forecasting has been the focus of many researchers to support the monitoring of aerosol impacts on climate, air quality, health, visibility [6]. The aerosol predictions are also been used for Radiances correction for data assimilation in numerical weather forecasting system. One of the model systems that were basically designed for Africa sector but now a global model is 
US Navy Aerosol Analysis and Prediction System (NAAPS) made by the Fleet Numerical Meteorological and Oceanography Centre (FNMOC). It is an offline aerosol model driven by Navy global meteorological models; the Navy Operational Global Analysis Prediction System (NOGAPS). In order for the model to be efficiently produce real-time aerosol forecasts multiple times per day, it contains necessary simplifications to its source functions, transport, chemistry, and removal processes [7]. Dust sources are defined in NAAPS using United State Geological Survey (USGS) Land Cover Characteristics Database. The database was created with the use of Advanced Very High Resolution Radiometer (AVHRR) data. Smoke emissions from biomass burning are derived from satellite-based thermal anomaly data of MODIS and Fire Locating and Modeling of burning Emissions (FLAMBE) database while the Sulfate which is a component of fine aerosols in NAAPS are derived from ECMWF MACC inventory.

Both the aerosol satellite monitoring and prediction are validated using ground-based measurements which can be completed by chemical analysis and particle counting such as AERONET [1]. AERONET is a network of Sun photometer which measures the extinction of the direct solar beam through the atmosphere. It provides dataset of spectral AOD with low uncertainty $(\sim 0.01$ $0.02)$ and high temporal resolution $(\sim 15 \mathrm{~min})$ under cloud-free conditions [8]. The purpose of this study is to examine agreement within the different methods of observation and to provide an indication of regional performance of the combined MODIS and NAAPS aerosol measurements.

\section{Datasets Used}

\subsection{MODIS}

The operational MODIS aerosol retrieval algorithms are of three separate algorithms; each requires separate assumptions about the Earth's surface and the expected aerosol types above these surfaces. The first comprises of two types that cover the dark vegetated land surfaces [1] and remote ocean areas [9], collectively denoted as "Dark-Target" algorithm which assumes low surface albedo for brighter surfaces. The third algorithm, is known as the Deep-Blue (DB) algorithm [10] which was designed for application over bright-desert regions. The Dark Target (Land and Ocean) retrieval algorithm is based on a "look-up" table (LUT) approach in which radiative transfer calculations are used to generate pre-computed theoretical outputs for a set of aerosol and surface parameters and compared with the observed radiation field [2]. Normalized solar radiance received at the TOA is a function of successive orders of radiation interactions, within the coupled surface-atmosphere system $\left(\theta_{0}, \theta, \phi\right)$. The TOA angular spectral reflectance $\left(\rho_{\lambda}\left(\theta_{0}, \theta, \phi\right)\right)$ at a wavelength of atmospheric path reflectance, the surface function, and environment function which always been neglected in order to have a good approximation as shown in equation below:

$$
\rho_{\lambda}^{*}\left(\theta_{0}, \theta, \phi\right)=\rho_{\lambda}^{a}\left(\theta_{0}, \theta, \phi\right)+\frac{T_{\lambda}\left(\theta_{0}\right) T_{\lambda}(\theta) \rho_{\lambda}^{s}\left(\theta_{0}, \theta, \phi\right)}{1-s_{\lambda} \rho_{\lambda}^{s}\left(\theta_{0}, \theta, \phi\right)}
$$


where $\rho_{\lambda}^{a}$ is atmospheric path reflectance, $T_{\lambda}\left(\theta_{0}\right)$ and $T_{\lambda}(\theta)$ are the downward and upward atmospheric transmissions, $s_{\lambda}$ is the atmospheric backscattering ratios, and $\rho_{\lambda}^{s}$ is the angular spectral surface reflectance.

All variables on the right hand side of Equation (1) except surface reflectance is a function of aerosol type and loading $(\mathrm{T})$ present in the atmosphere. In the case of Ocean, the surface calculation includes sun glint reflection off the surface waves, reflection by whitecaps and Lambertian reflectance from underwater scattering (sediments, chlorophyll, etc.). The aim of the algorithm is to use the LUT to determine the conditions that best imitate the MODIS-observed spectral reflectance $\rho_{\lambda}^{m}$, and retrieve the associated aerosol properties. The TOA reflectance measured at resolutions ranging from $250 \mathrm{~m}$ in the shortwave visible wavelengths to $500 \mathrm{~m}$ in the near-infrared and is then aggregated to boxes of 20 by 20 or 10 by $10 \mathrm{~km}$ resolution at nadir for aerosol retrieval [2]. The Ocean algorithm is used for retrieval if all pixels within the $20 \times 20$-pixel box are water; otherwise, the Land algorithms are used. And a simple union of the AODs derived from the Land and Ocean algorithms make up the MODIS, level 2, "Land_And_Ocean" AOD product that is popularly used by the research community.

MODIS Deep blue algorithm also uses the TOA reflectance to retrieve AOD data at nominal spatial resolution of $1 \mathrm{~km}$ by $1 \mathrm{~km}$ at the sub-satellite point (412, 470 , and $650 \mathrm{~nm}$ ), with only $650 \mathrm{~nm}$ band used over desert on the evolvement of high dust aerosol loading or thick cloud. The 1 by $1 \mathrm{~km}$ pixel is averaged to 10 by $10 \mathrm{~km}$ retrieval scale and flag into different Quality Assurance (QA) [11]. The surface reflectance assumed in the retrieval algorithms is prescribed from one of a variety of methods dependent on location/surface type, solar/sensor geometry and normalized difference vegetation index (NDVI) which is define as shown below [12].

$$
\mathrm{NDVI}=(\mathrm{R} 0.86-\mathrm{R} 0.65) /(\mathrm{R} 0.86+\mathrm{R} 0.65)
$$

where R0.65 and R0.86 correspond to the TOA reflectance measured at 0.65 and $0.86 \mu \mathrm{m}$, respectively. The radiance was assumed to be dominated by Rayleigh scattering and bounded by a Lambertian surface. A maximum likelihood (probability) method is used to match the appropriate values of aerosol optical thickness and mixing ratio to the measured reflectance after reflectance has been compared with that of LUT reflectance comprising of Lambertian Equivalent Reflectivity (LER) [10]. Reference [11] indicated that there were no significant differences between MODIS/AERONET comparability for the two MODIS instruments (MODIS Terra and MODIS Aqua).

\subsection{NAAPS}

The model contains four prognostic aerosol/trace gas species: gaseous $\mathrm{SO}_{2}$, particulate sulfate, soil dust, and smoke. All four species are treated as passive tracers (i.e. they do not interact with the model fields or with each other), and are tracked by mass alone. NAAPS model produces 120 hour forecasts of its com- 
ponent aerosol species every six hours on a $1^{\circ} \times 1^{\circ}$ horizontal grid. It is designed based on Danish Eulerian Hemispheric Model, finite element horizontal diffusion and finite element vertical transport. The output products are functions of some physical events such as surface wind speed, surface type, ground wetness, stress, threshold velocity, cloud type, stability, and size bin. Also some mentioned variables are related to each other in the model domain e.g. Friction velocity, $V$, is related to the wind speed, $W$, at some reference height, $r$, as shown by Equation (3). Dust is emitted from the surface when the friction velocity exceeds a threshold value $(60 \mathrm{~cm} / \mathrm{s})$ and the surface moisture is below a critical fraction value of 0.3 [7]. An assumption that is based on study of mobilization and transport of Saharan dust [13] and thus may not be entirely appropriate for all dust-producing areas of the world

$$
V=\left(C_{D} W_{r}^{2}\right)^{\frac{1}{2}}
$$

where $C_{D}$ denotes the drag coefficient.

All aerosol species in NAAPS are subjected to dry and wet removal processes. Gravitational settling is not parameterized as a removal process in NAAPS, given that gravitational settling is an efficient removal process for large dust particles [14].

\subsection{AERONET}

AERONET represents a standard resource for the validation and bias-correction of satellite AOD datasets [2] [11]. This is because of its high data quality, consistency of processing standards, wide global range of sites, and free and simple data access. It derives AOD from direct sun photometer measurements in some or all of the following eight different spectral bands centred at 340, 380, 440, 500, 670, 940, 1020 and $1064 \mathrm{~nm}$. Although the wavelengths at which AOD is reported vary from sites to sites and can vary for different periods at a given site [8]. NAAPS forecasts are also been validated using AERONET by converting the forecasts to AOD, been the widest available tool for estimating total aerosol amount, and using it to build a timeline to compare the magnitudes and temporal variability of aerosol over specific location [13]. In this study, Version 2 Level 2 data screened from cloud contamination and quality-assured [15] direct-Sun AOD retrieval is used for the five sites over North Africa. The stations were chosen for their large data records and to provide a representative set of geometric, atmospheric, and surface conditions. The sites selected are as shown in Figure 1. The region selected is very important to the global aerosol loading and because of the complexity of the surface (bright in the Sahara and less bright in Sahel follow by vegetated cover towards the coast of Atlantic). It is a good site to test the validation of combined MODIS retrieval and the accuracy of the model.

\section{Methodology}

To validate satellite and model AOD data different methods are adopted but 


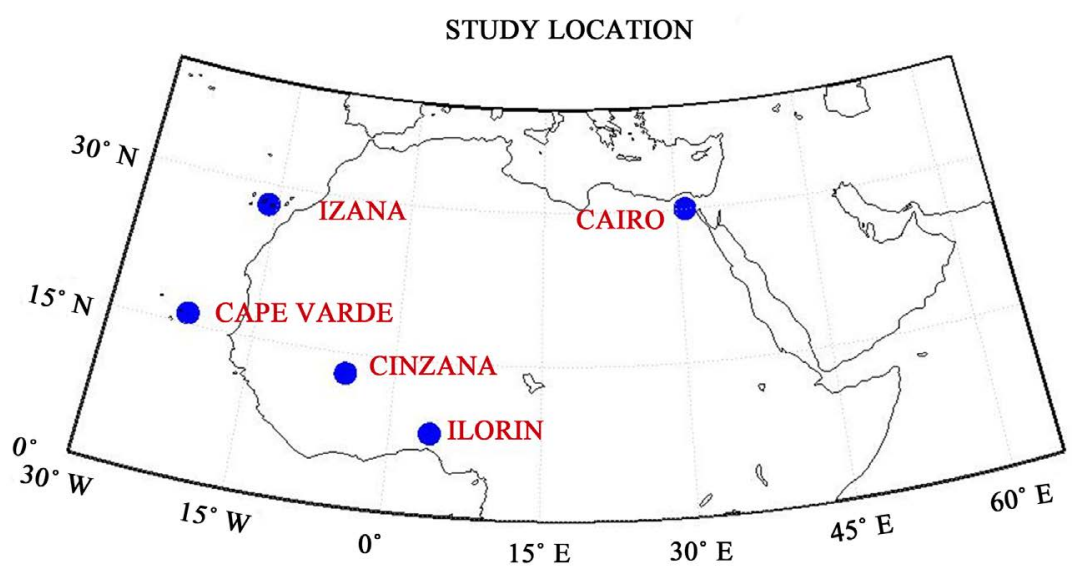

Figure 1. Geographical boundary used in this study with the blue dot showing AERONET sites.

with the same conditions of spatial and temporal matching with the usage of quality assured and cloud screened data. In the case of satellite, it provides pictures of a larger region at a single time while AERONET provides a point measurement repeatedly. AERONET instruments collect data in multiple wavelengths many of which are slightly different from the MODIS channels. Aeronet data in $500 \mathrm{~nm}$ channels is converted to MODIS $550 \mathrm{~nm}$ channels for all the sites selected using a standard Ångström exponent $\alpha$ at wavelength pair of 500/870 $\mathrm{nm}$ [16], defined

$$
\alpha=-\frac{\ln \left(\tau_{1} / \tau_{2}\right)}{\ln \left(\lambda_{1} / \lambda_{2}\right)}
$$

where $\tau_{1}$ and $\tau_{2}$ are the $\mathrm{AOD}_{s}$ at wavelengths $\lambda_{1}$ and $\lambda_{2}$ respectively. Insignificant uncertainty is introduced through this spectral interpolation. Temporal average of AERONET dataset around the time $( \pm 30 \mathrm{~min})$ of the satellite overpass are taken with at least two direct sun level 2 measurements, as well as spatial average of the satellite data over the selected ground site. In this case, AERONET AOD data were averaged, within $30 \mathrm{~min}$ of the MODIS (Terra and Aqua) overpass in local time of individual site, extracted and used to validate MODIS data averaged within $27.5 \mathrm{~km}$ radius of the AERONET site. Performance of the retrieval is tested across the region using statistical tools such as correlation, fractional error (FE), index of agreement (IA), root mean square error (RMSE), and slope of MODIS/AERONET regression. The IA which is the ratio of the errors gives standardized measure of the degree of model prediction error and varies between 0 and 1 . A value of 1 indicates a perfect match, and 0 indicates no agreement at all, this provides improvement over the coefficient of determination [17].

$$
\text { Fractional Error }=\frac{1}{n}\left[\frac{\sum_{1}^{n}|M-O|}{\sum_{1}^{n}\left(\frac{(M+O)}{2}\right)}\right]
$$




$$
\text { Index of Agreement }=1-\left[\frac{\sum_{1}^{n}(O-M)^{2}}{\sum_{1}^{n}(|M-\bar{O}|+|O-\bar{O}|)^{2}}\right]
$$

where $M$ is retrieved/predicted concentration, $O$ is observed concentration, and $n$ is sampling population.

NAAPS validation is executed by converting the forecasts to AOD at $500 \mathrm{~nm}$ wavelength because AERONET Spectral Deconvolution Algorithm (SDA) Retrievals that is used for its validation produce AOD of both fine and coarse mode at $500 \mathrm{~nm}$. Both data sources must match spatially and temporally for good comparison. The forecast conversion is done for each of the three aerosol species using the following mass extinction efficiencies: $0.56 \mathrm{~m}^{2} \cdot \mathrm{g}^{-1}$ for dust; $7.1 \mathrm{~m}^{2} \cdot \mathrm{g}^{-1}$ for smoke; and 4.5, 5.1, 7.2, 15.0, and $31.6 \mathrm{~m}^{2} \cdot \mathrm{g}^{-1}$ for sulfate at relative humidity values of $30 \%, 50 \%, 70 \%, 90 \%$, and $98 \%$, respectively [7]. Real-time global surface concentration and aerosol optical depth forecasts for the three particulate species in NAAPS are available at http://www.nrlmry.navy.mil/aerosol/. Aerosol species advection and Air mass trajectories were investigated over the study location using National Oceanic and Atmospheric Administration (NOAA) Hybrid Single Particle Lagrangian Integrated Trajectory (HYSPLIT) model. HYSPLIT was used for single particle calculations backwards in time from the source to the sink points (AERONET stations) ending at surface altitude of $500 \mathrm{~m}, 1000 \mathrm{~m}$, and $2000 \mathrm{~m}$. The simulation was done with the maximum number of Seven day backward-trajectories falling into different season of the year. Maximum runtime of 180 hours was chosen with markers every 12 hours along trajectories (Figure 5). The Global Data Assimilation System (GSFG) meteorological dataset was used as input which has a temporal resolution of 6 hours and a horizontal resolution of $1^{\circ}[18]$.

\section{Results}

In this section we show, on one hand, the agreement within the combined MODIS-AERONET AOD at $550 \mathrm{~nm}$ and NAAPS-AERONET at $500 \mathrm{~nm}$. On the other hand, we investigate statistically the performance of the MODIS (Land/Ocean and Terra/Aqua) over the North Africa region. Hereafter the MODIS, AERONET and NAAPS AOD are denoted as $\tau_{M}, \tau_{A}$ and $\tau_{N}$ respectively.

\subsection{MODIS Validation Result}

The validation of $\tau_{M}$ with $\tau_{A}$ for the resulting matched dataset is as shown in Figure 2. The $\tau_{M}$ and $\tau_{A}$ show statistical significant correlation $(R>0.5)$ in almost all the sites except in Izana with correlation value below average. This may be due to location of the photometer in the Izana site which is above temperature inversion layer (2391.0 $\mathrm{m}$ above ground level) [19] [20].

Also, the majority of the data (70\%) in almost all the site are for high aerosol loading $\left(\tau_{A} \leq 0.6\right)$ except that of Izana which is of low aerosol loading $\left(\tau_{A} \leq 0.1\right)$. 

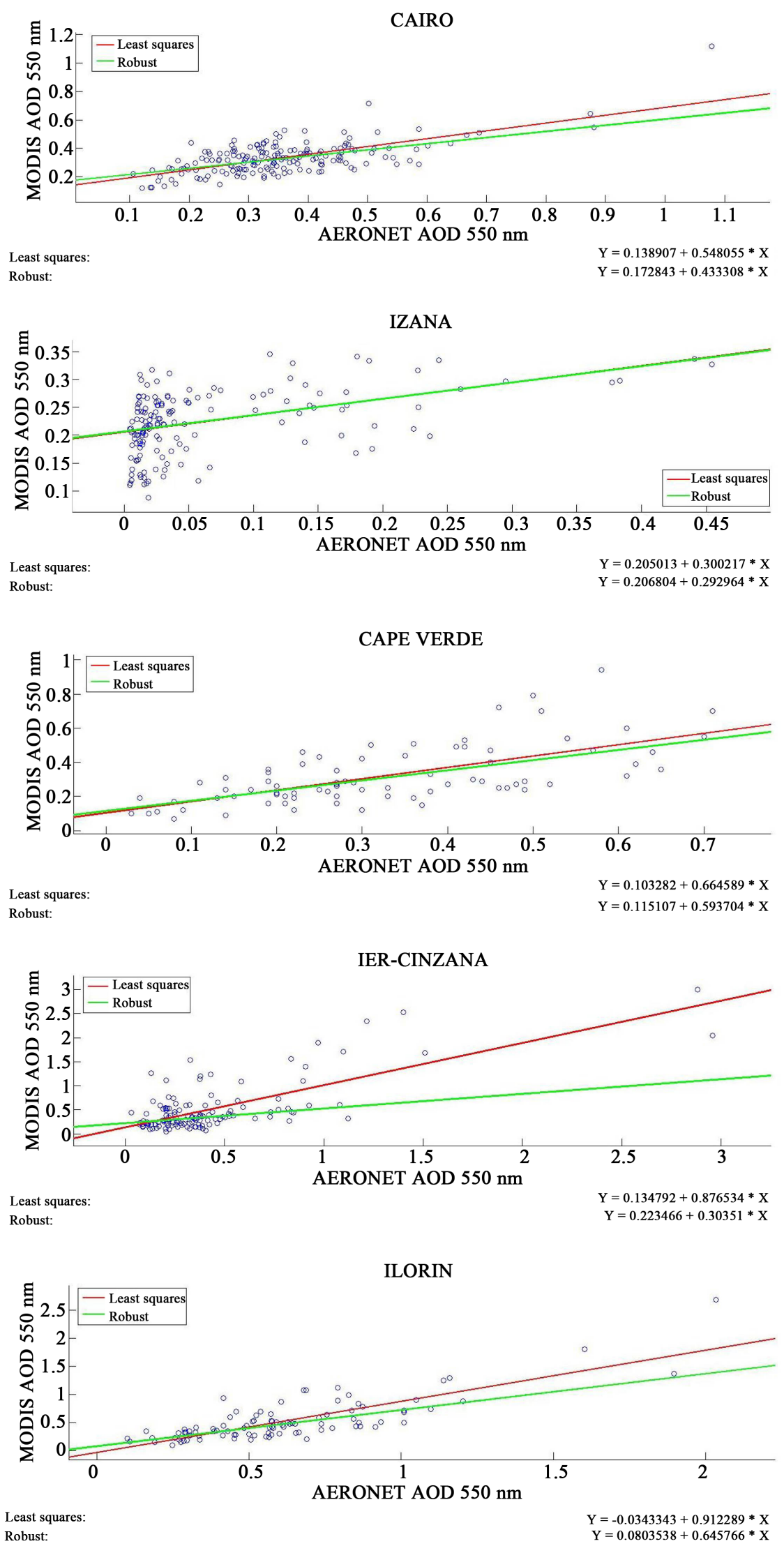

Figure 2. Scatter robust fitting plots showing validation results of $\tau_{M}$. 
This means that the contribution of aerosols to TOA radiance received by MODIS in Izana is minimal and is mainly from surface and Rayleigh scattering. Aerosols in other sites considered have a significant contribution to the TOA radiance received by the sensor although there are some conditions in which TOA radiance is insensitive to high aerosol loading [21]. The slope of least square regression fit $(\mathrm{M})$ and $\mathrm{y}$-intercept are elements that can show biases between the two measurement methods. All the five sites considered are found to have a regression with positive slope indicating a systematic positive bias in $\tau_{M}$ as $\tau_{A}$ increases. The bias may evolved due to overestimation of the surface reflectance contribution to the radiance measured by the satellite at the TOA which intends leads to an underestimation of AOD [22]. Furthermore, all the sites show positive $y$-intercept of the value $>0.1$ except Ilorin with negative intercept of value -0.03 . Figure 2 also shows that the absolute error in AOD retrieved is generally larger for high AOD conditions than for clean conditions across the sites.

If the time frame is shrunk to $15 \mathrm{~min}$ or expanded to $60 \mathrm{~min}$, and the spatial window bounded to consider only the MODIS retrieval in these time bounds over AERONET site, the data volume decreases or increases by a factor of $\sim 2$ while results change negligibly. This indicates that the majority of the disagreement between MODIS and AERONET is likely due to other factors such as systematic uncertainties in aerosol/surface properties for a given time and location, rather than radiometric noise or true spatiotemporal variability.

\subsection{Regional Performance of Combined MODIS}

Validation statistics for the combined MODIS (land and ocean) + terra and aqua over the North Africa region is as shown in Figure 3. It is observed that there is spatial variation in retrieval performance majorly due to differing local uncertainties in assumed surface reflectance, performance of cloud-screening tests and microphysical properties of the aerosol. The variability of $\tau$ over the region shows Ilorin a Sub-Sahel station having the highest mean value $>0.6$ followed by the Cinzana in Sahel and the least is deep in the Sahara. This may be as a result of different aerosol types and composition that exist in each location. The validation correlation follows the same trend over the region as the mean $\tau$ i.e. best $(0.81)$ in the Sub-Sahel, better (0.73) in Sahel and fair in deep Sahara $(0.65 / 6)$ and marine areas (0.45) as shown in Figure 3(b). To further evaluate if MODIS aerosol products represent the statistics observed from AERONET, the mean bias (MB), root mean square error (RMSE), index of agreement (IA), t-test and fractional error (FR) are used to assess the accuracy of MODIS over the region. They are ways of measuring how good predictive method is over the actual observation, they can be considered individually of in group.

The RMSE (variance) is an inverse of precision i.e. the higher its value the lesser the precision and bias gives information about over/under estimation in either positive/negative direction of predicted over the observed. Figure 3(c) \& Figure 3(f) show the RMSE and MB over the study location, the retrieval accuracy assessment results show that Ilorin has the highest value of RMSE and least 


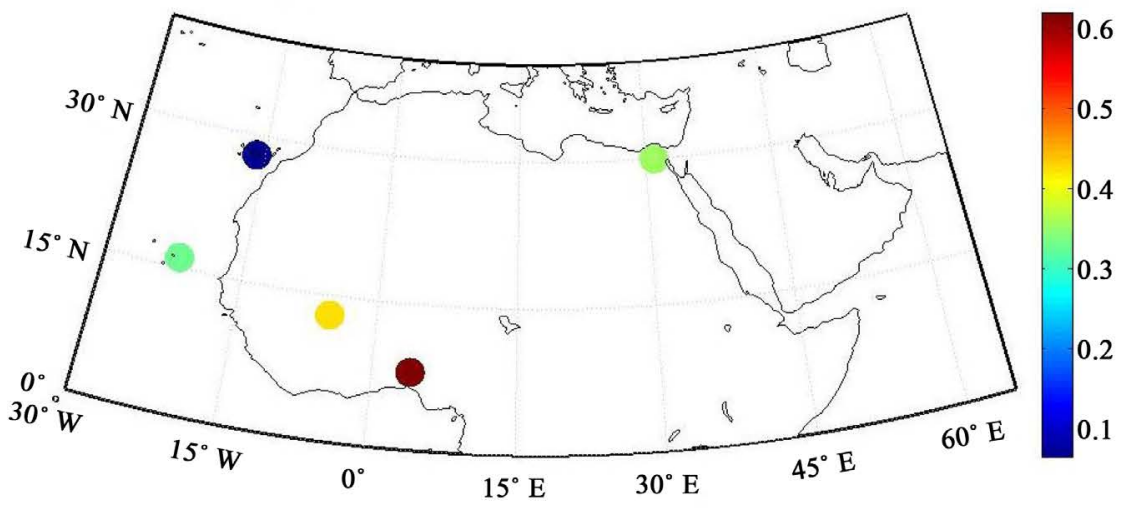

(a)

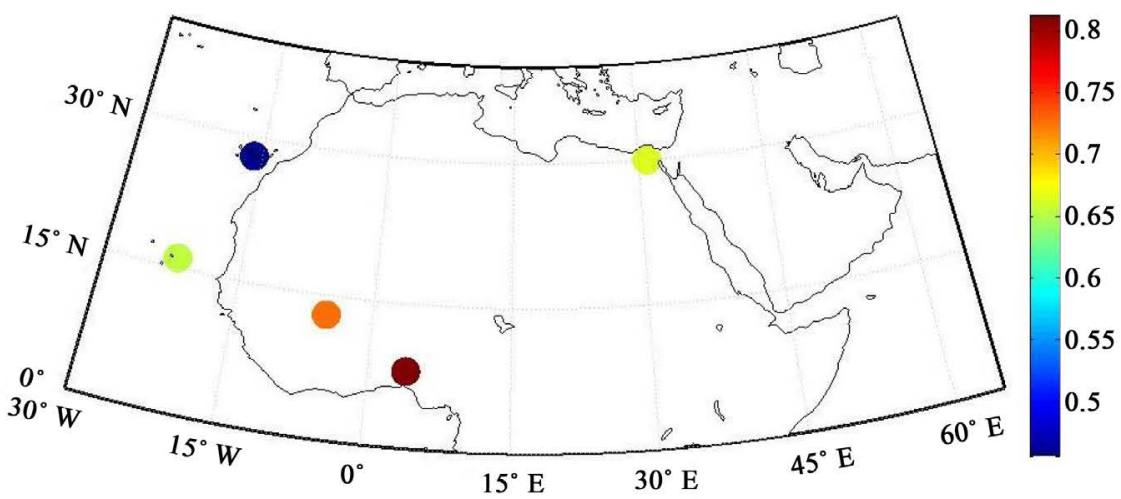

(b)

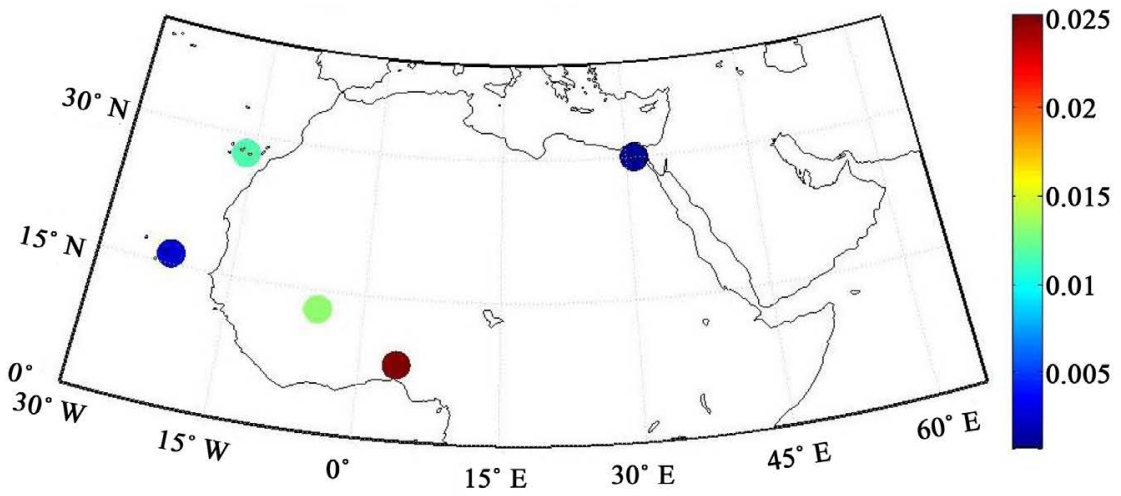

(c)

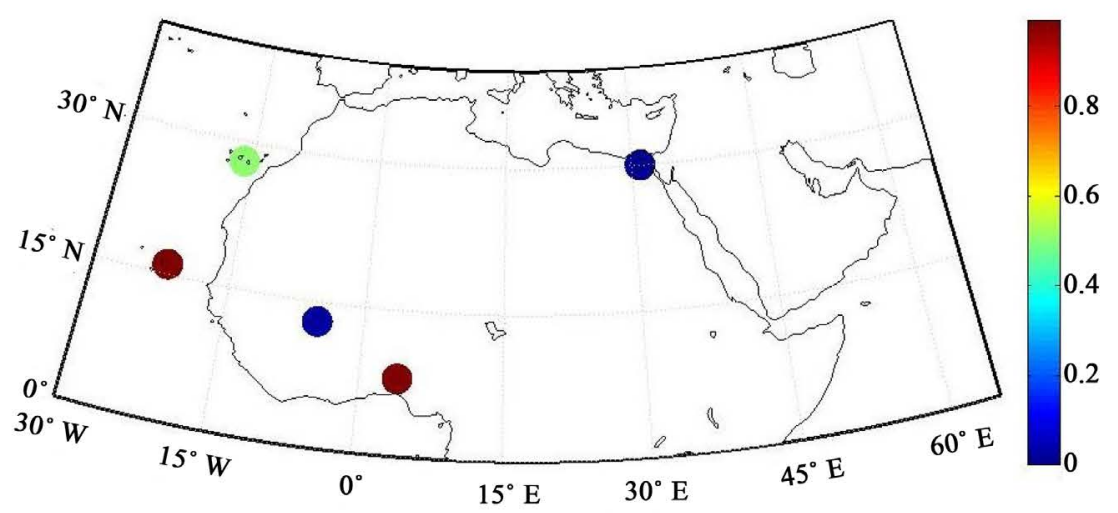

(d) 


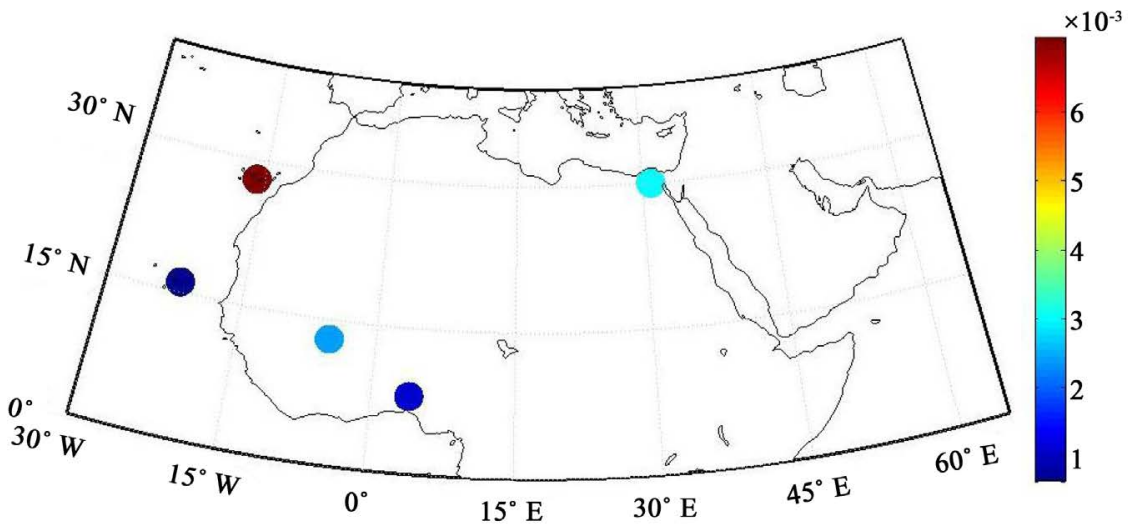

(e)

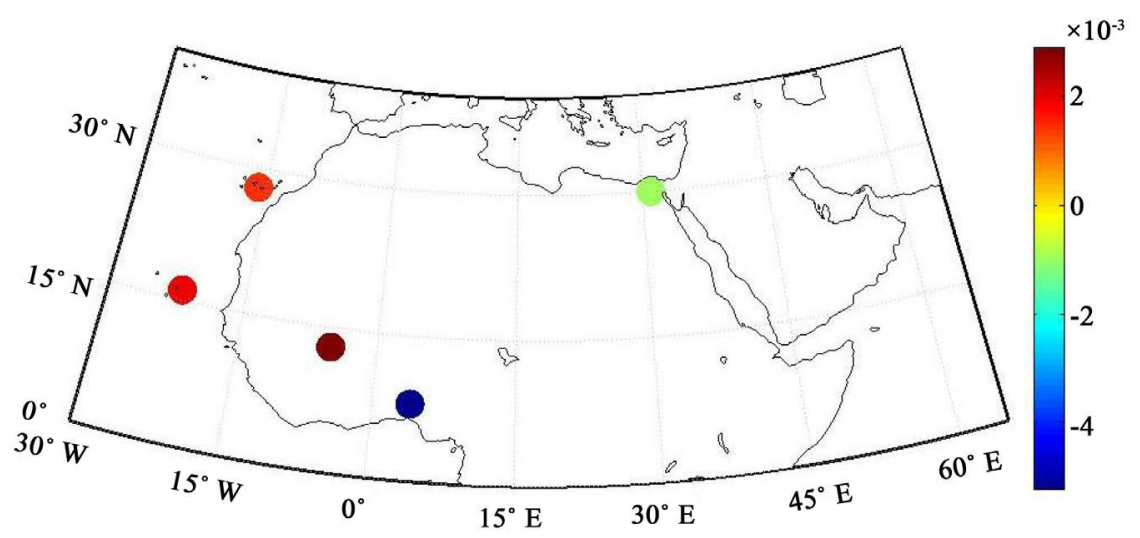

(f)

Figure 3. Regional variability of validation statistics for $\mathrm{AOD}_{550 \mathrm{~nm}}$. (a) Mean AERONET $550 \mathrm{~nm}$ AOD; (b) Correlation coefficient; (c) Root mean square error; (d) Index of agreement; (e) Fractional error; (f) Mean bias.

value of $\mathrm{MB}$ in negative direction followed by Cinzana and Izana but with a positive MB value, lastly Cape Verde and Cairo have the least RMSE with positive and negative bias respectively. Considering the two factors together, it indicates that combined MODIS in study location has good retrieval performance over Cape Verde and Cairo but a fair one over Ilorin, this is because of large variance shown through the value of RMSE when compare to AERONET dataset. Negative bias shown by Cairo site makes the performance weaker than that of Cape Verde despite the least value of RMSE possessed. Negative biases could indicate insufficient absorption in aerosol properties assumed in this region, overestimates of surface reflectance, or perhaps issues associated with sub-retrieval heterogeneity or over-zealous cloud-flagging of some aerosol plumes [11].

Going beyond biases testing, we apply IA and FE testing to further ascertain the degree of retrieval prediction error as described by [17]. IA varies between 0 and 1 , a value of 1 indicates a perfect match and 0 indicates no agreement at all. The associated error is indicated with the value of FE and the smaller the value the better the performance. The tests result as shown in Figure 3(d) \& Figure 
3(e) return high IA with minimal FE value for Cape Verde making the MODIS retrieval over the site most agreeable with the AERONET dataset. However, to fully describe the fit between MODIS and AERONET data, our analysis is extended to t-test (pair-sample) for difference of mean to evaluate the level of significant difference between the MODIS and AERONET using the t-value derived.

The result of the t-test is as shown in Table 1(a) \& Table 1(b), the standard deviation (SD) and standard error (SE) provided by t-test result tell us how much the $\tau$ were spread out around the means and an estimate of how much variation we are likely to get in the means if we repeated the measurement many times respectively. Looking at the difference between the means of the two methods over the sites in relation to the size of SD and SE, Cape Verde give a very small difference (SE: 0.0195541/0.0192178) compared to the other site, suggesting that there is probably no significant difference between the two measurement methods over the location.

Table 1. (a) Paired samples statistics; (b) Paired sample t-test result.

(a)

\begin{tabular}{cccccc}
\hline & & Mean & $\mathrm{N}$ & Std. Deviation & Std. Error Mean \\
\hline \multirow{2}{*}{ Pair 1 } & IZNMODIS & 0.223909 & 154 & 0.0568176 & 0.0045785 \\
& IZNAERO & 0.062943 & 154 & 0.0860793 & 0.0069365 \\
Pair 2 & CARMODIS & 0.332785 & 179 & 0.1127806 & 0.0084296 \\
& CARAERO & 0.353758 & 179 & 0.1362496 & 0.0101838 \\
Pair 3 & CPVMODIS & 0.319359 & 78 & 0.1726970 & 0.0195541 \\
& CPVAERO & 0.325128 & 78 & 0.1697266 & 0.0192178 \\
Pair 4 & CZNMODIS & 0.507569 & 130 & 0.5090731 & 0.0446487 \\
& CZNAERO & 0.425286 & 130 & 0.4214924 & 0.0369673 \\
Pair 5 & ILRMODIS & 0.528670 & 94 & 0.3791282 & 0.0391041 \\
& ILRAERO & 0.617129 & 94 & 0.3370643 & 0.0347655 \\
\hline
\end{tabular}

(b)

\begin{tabular}{|c|c|c|c|c|c|c|c|c|c|}
\hline & \multicolumn{6}{|c|}{ Paired Differences } & \multirow[b]{2}{*}{$\mathrm{t}$} & \multirow[b]{2}{*}{$\mathrm{df}$} & \multirow[b]{2}{*}{$\begin{array}{c}\text { Sig. } \\
\text { (2-tailed) }\end{array}$} \\
\hline & & Mean & $\begin{array}{c}\text { Std. } \\
\text { Deviation }\end{array}$ & $\begin{array}{l}\text { Std. } \\
\text { Error } \\
\text { Mean }\end{array}$ & $\begin{array}{r}95 \% \text { Cor } \\
\text { Interva } \\
\text { Diffe }\end{array}$ & $\begin{array}{l}\text { Ifidence } \\
\text { l of the } \\
\text { cence }\end{array}$ & & & \\
\hline Pair 1 & $\begin{array}{l}\text { IZNMODIS- } \\
\text { IZNAERO }\end{array}$ & 0.1610 & 0.079 & 0.006 & 0.1484 & 0.1735 & 25.392 & 153 & 0.000 \\
\hline Pair 2 & $\begin{array}{c}\text { CARMODIS- } \\
\text { CARAERO }\end{array}$ & 0.0210 & 0.105 & 0.008 & -0.0364 & -0.0055 & -2.683 & 178 & 0.008 \\
\hline Pair 3 & $\begin{array}{l}\text { CPVMODIS- } \\
\text { CPVAERO }\end{array}$ & -0.0058 & 0.143 & 0.016 & -0.0379 & 0.0264 & -0.357 & 77 & 0.722 \\
\hline Pair 4 & $\begin{array}{c}\text { CZNMODIS- } \\
\text { CZNAERO }\end{array}$ & 0.0823 & 0.354 & 0.031 & 0.0208 & 0.1437 & 2.650 & 129 & 0.009 \\
\hline Pair 5 & $\begin{array}{l}\text { ILRMODIS- } \\
\text { ILRAERO }\end{array}$ & -0.0885 & 0.224 & 0.023 & -0.1343 & -0.0426 & -3.833 & 93 & 0.000 \\
\hline
\end{tabular}


In addition to this, the mean difference, confidence interval and t-value with its significant level results show the observed difference of Cape Verde could easily be in entirely the opposite direction if we conduct the experiment again i.e. AERONET might be a little over estimated than MODIS and vice versa. The agreement between the combined MODIS and AERONET over the Cape Verde is highly unlikely to have occurred by chance due to high significant figure of 0.72 and straddling of confidence interval around zero. The variability in performance across the locations in the region indicates potential foci point for future algorithmic developments, or development of a more advanced error model.

Comparing the work with other validations in the region such as Deep Blue and Dark Target retrievals, this work out performed the DT anywhere in the region due to the surface assumptions made in the DT algorithm [3] [23]. In the case of DB retrieval, the combined MODIS retrieval adopted here performed better in Sub-Sahel and Sahel region likewise in the Ocean areas of the region in term of correlation coefficient (CC) and expected error (EE). But in the main land in the deep Sahara the DB retrieval performed better with higher correlation value [11] [12].

\subsection{NAAPS Validation Result}

The output of the forecast is in surface concentration of the component aerosol particles in $\mu \mathrm{g} \cdot \mathrm{m}^{-3}$ and their intensities and spatial extent vary from season to season. The simulated aerosols over the region can be seen year round with different components such as dust, smoke, and sulfate occupying different part of the region based on the season as shown in Figure 4. Maximum dust and smoke surface concentration extend from northern Sahara to south and Southern Sub-Sahel to the north respectively with little presence of sulfate from Europe in the region. The spatial distribution of the aerosol species can be explained by transport and precipitation pattern over the study location.

The air masses coupled with pressure height brings about dragging, suspension, and settling of the aerosol particles while rainout scavenge the aerosol in the atmosphere. Therefore, prediction of high surface aerosol concentration in a region of high average annual rainout like part of the study area may be attributable to northward shift of the Inter-tropical discontinuity (ITD) pushing the dust far north and over the Atlantic. Thus, maximum over-ocean precipitation rates are realized concurrently as that total column dust loadings are maximized over the western part of the region [7].

The air mass seven day backward trajectories run over the region ending at AERONET sites selected for the representation of the seasons shows that the high surface aerosol concentration is as a result of descending air masses from both Atlantic and across the inter land with little scavenging due to rainout (Figure 5).

The NAAPS validation result is produce in timeline over each AERONET site selected in the region and comparisons are made in term of aerosol magnitude and compositions (sizes) over time (Figure 6). Some of the sites selected (Izana 
AOD

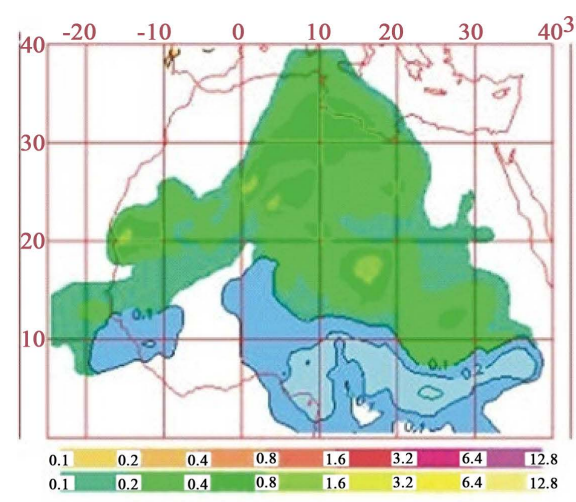

Sulfates (Microgram per cubic meter)

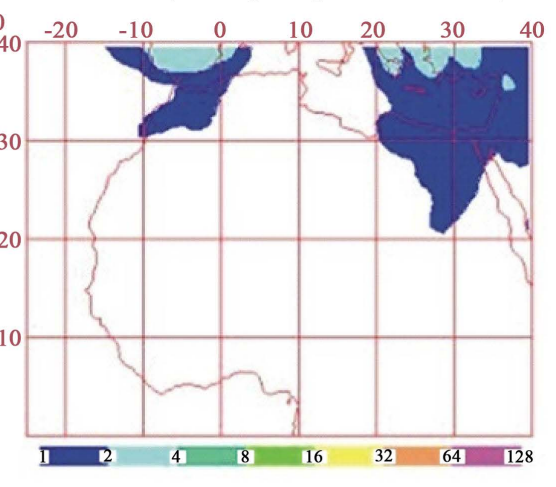

Dust (Microgram per cubic meter)

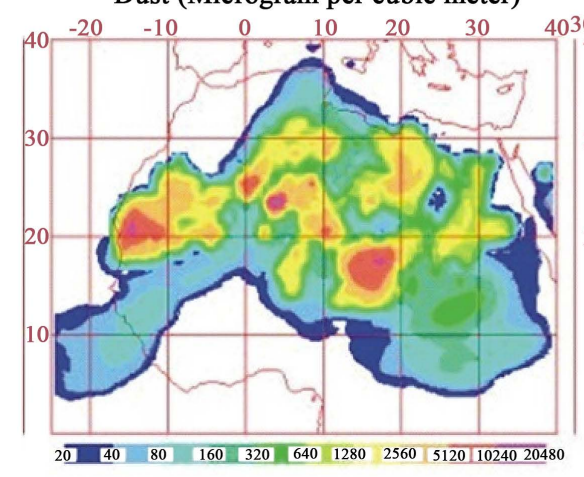

Smoke (Microgram per cubic meter)

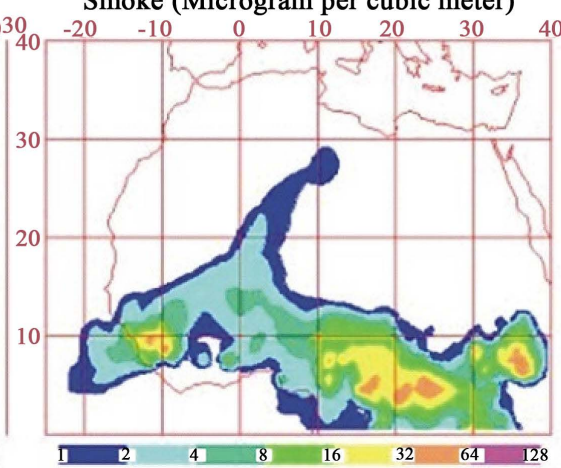

DJF
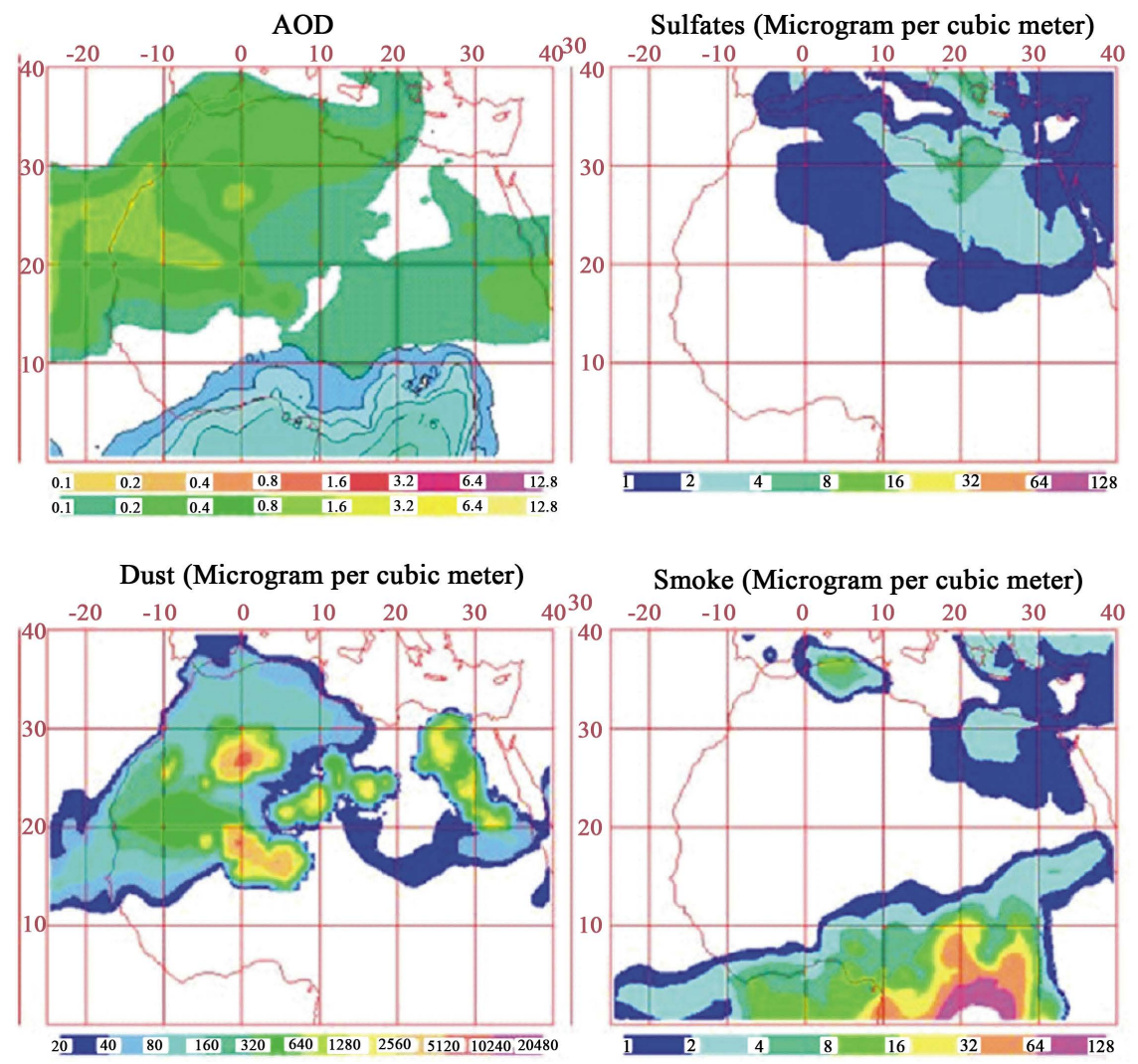

MAM 


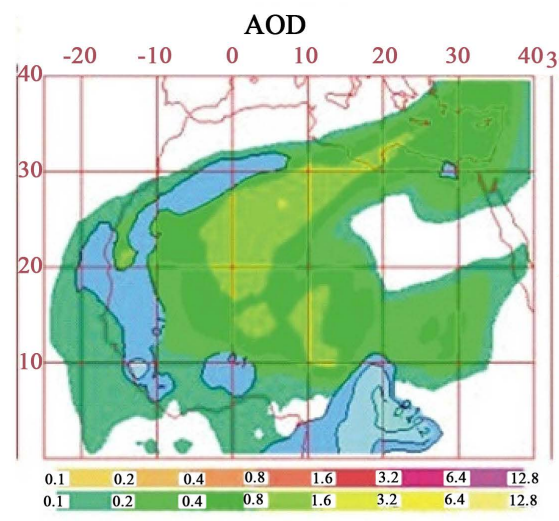

Sulfates (Microgram per cubic meter)
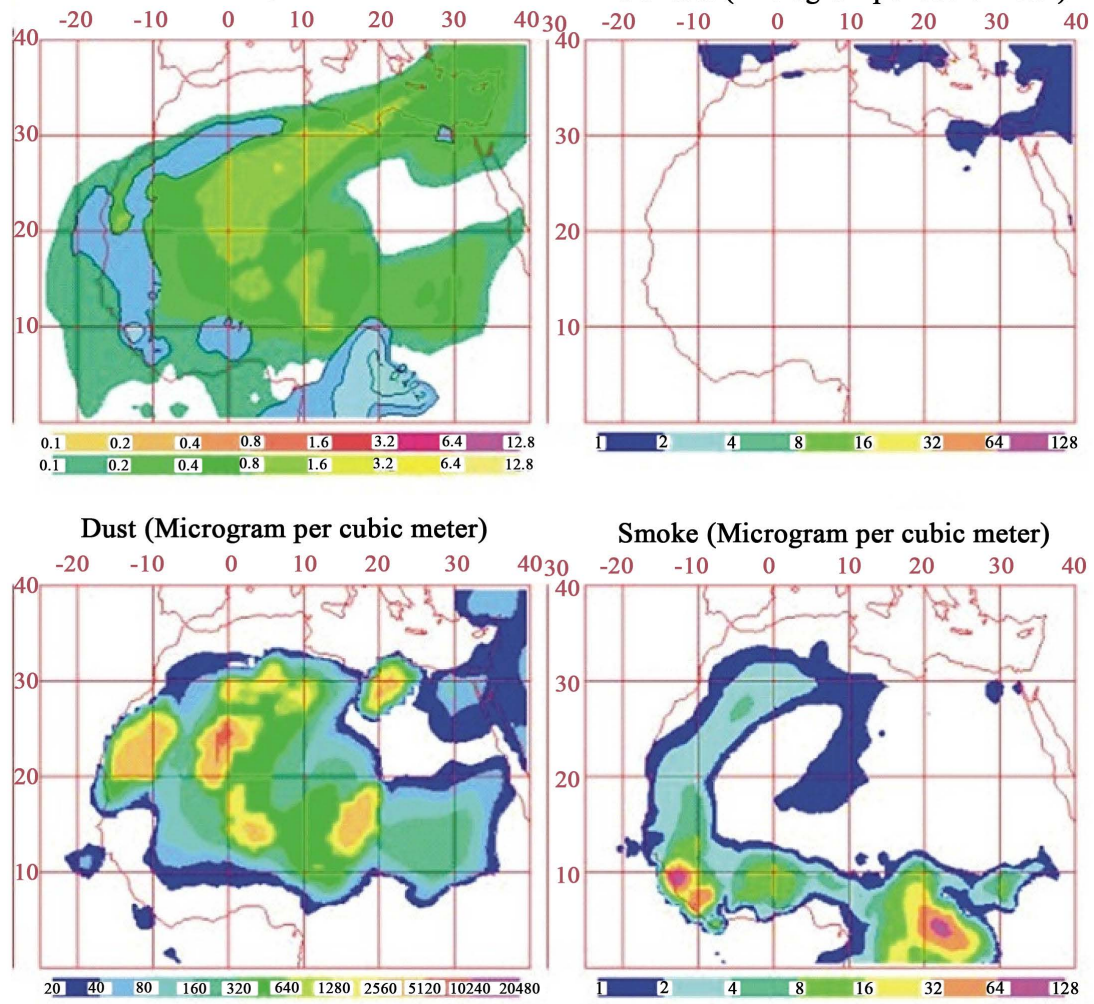

Smoke (Microgram per cubic meter)

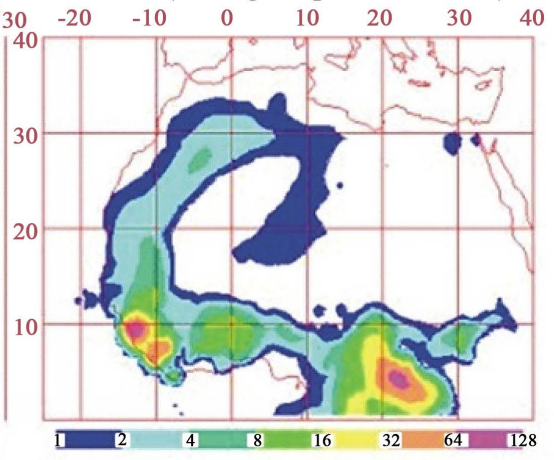

JJA

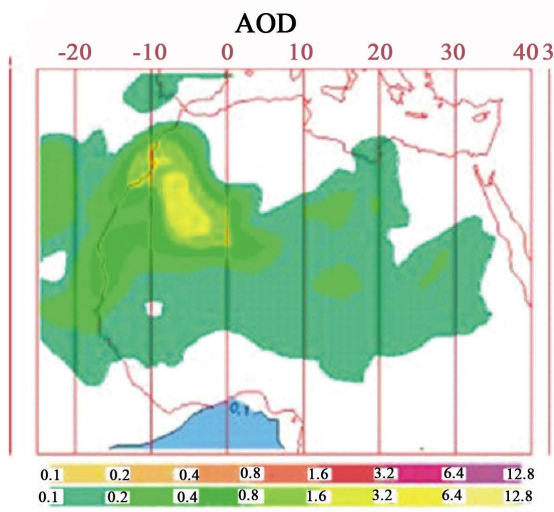

Sulfates (Microgram per cubic meter)
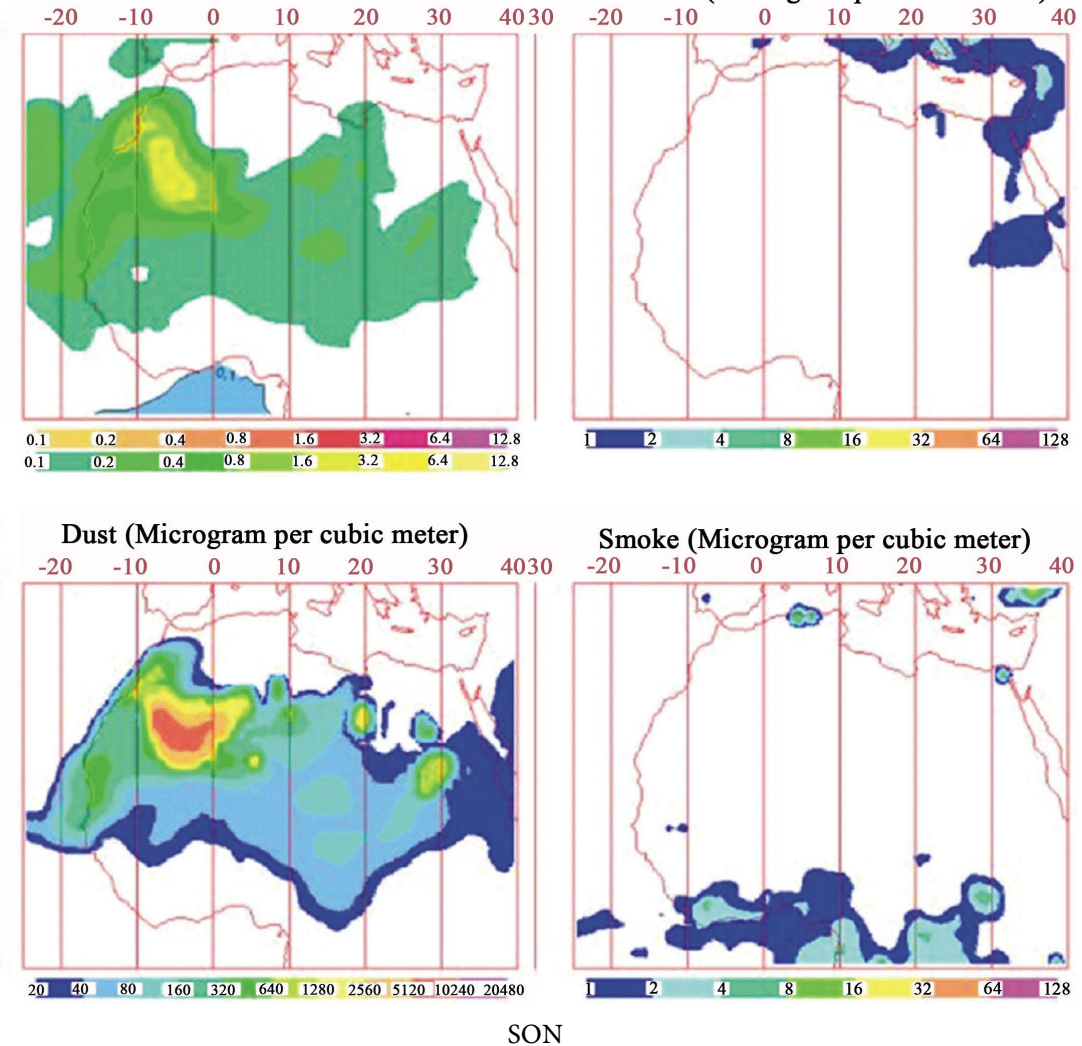

Figure 4. 2006 seasonal representation of NAAPS surface concentration $\left(\mu \mathrm{g} \cdot \mathrm{m}^{-3}\right)$. 
NOAA HYSPLIT MODEL

Backward trajectories ending at 1200 UTC 15 Jan 06

GDAS Meteorological Data

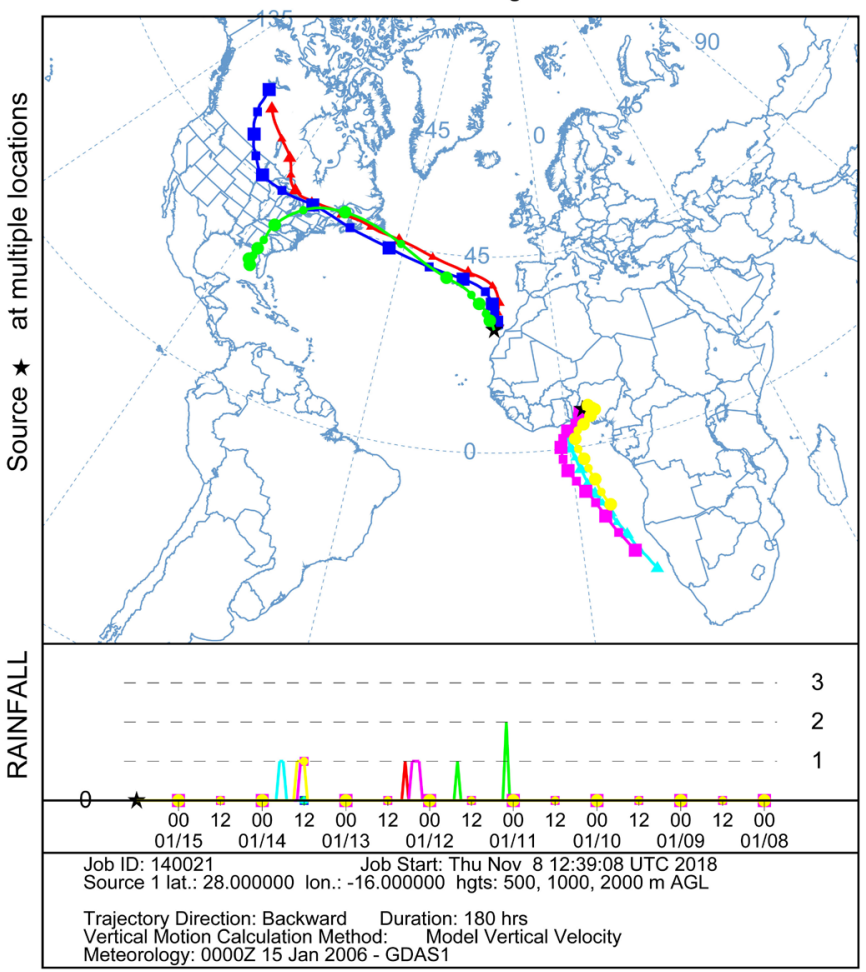

(a)

NOAA HYSPLIT MODEL

Backward trajectories ending at 1200 UTC 18 Apr 06

GDAS Meteorological Data

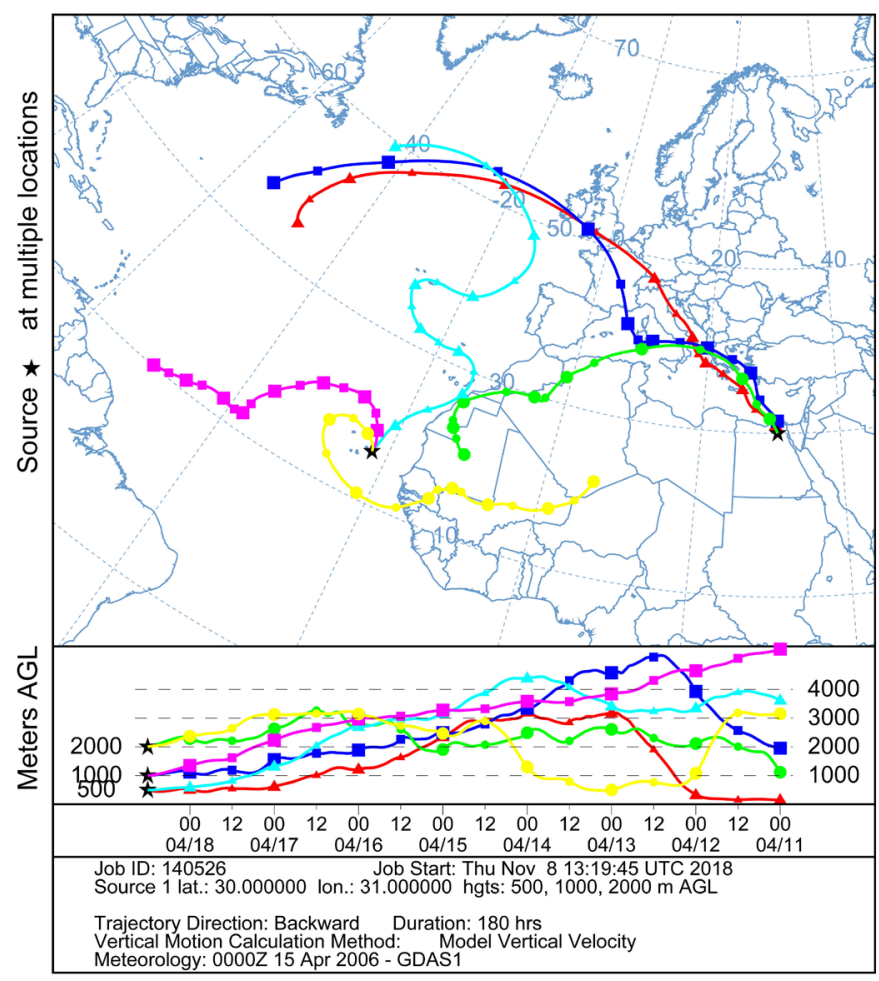

(b) 
NOAA HYSPLIT MODEL

Backward trajectories ending at 1200 UTC 18 Jan 06 GDAS Meteorological Data

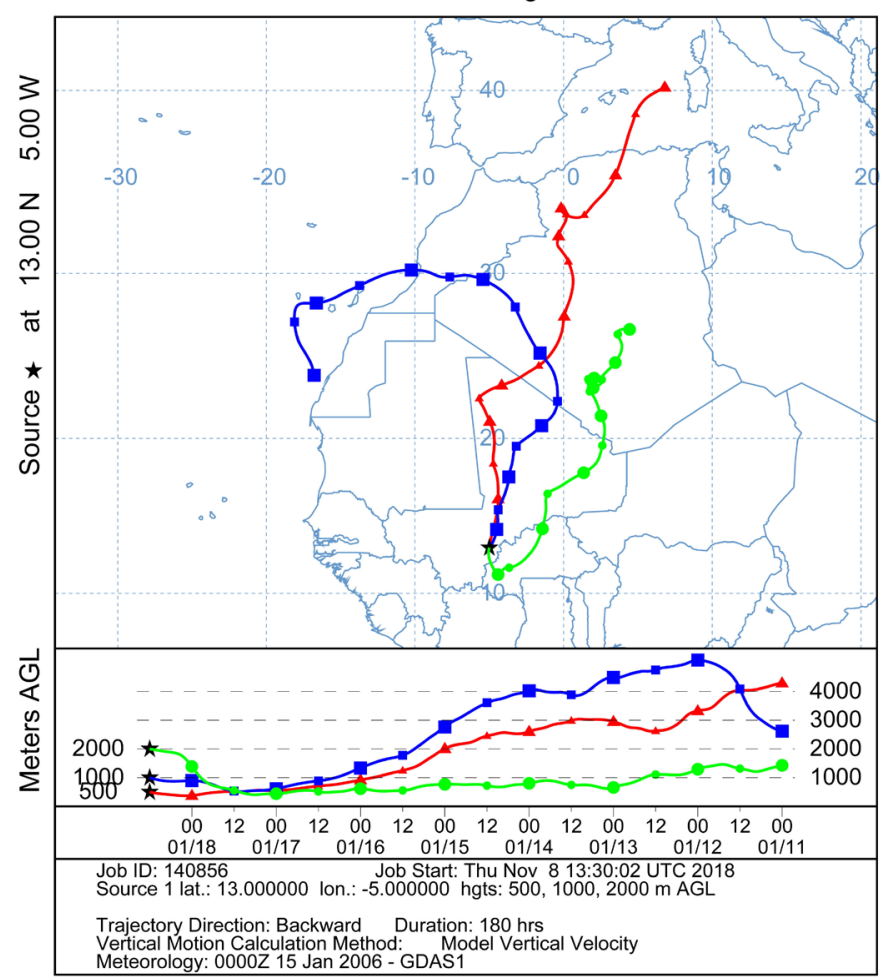

(c)

NOAA HYSPLIT MODEL

Backward trajectories ending at 1200 UTC 18 Apr 06 GDAS Meteorological Data

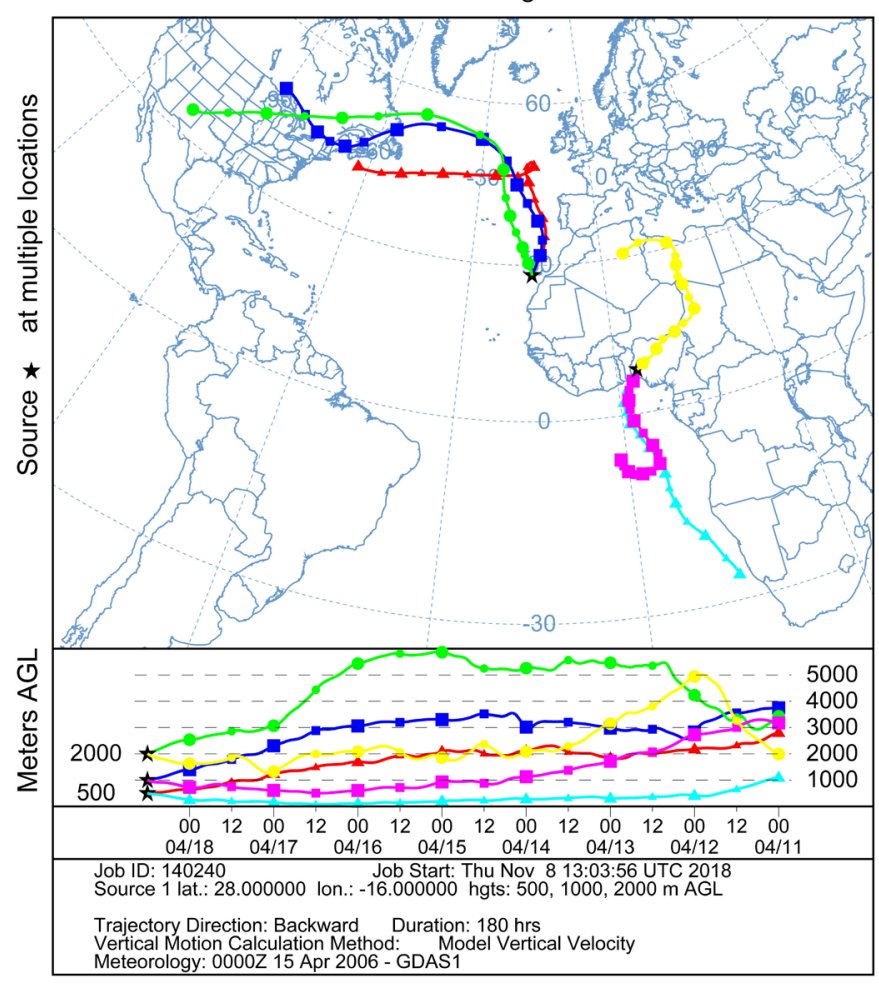

(d) 
NOAA HYSPLIT MODEL

Backward trajectories ending at 1200 UTC 18 Jul 06

GDAS Meteorological Data

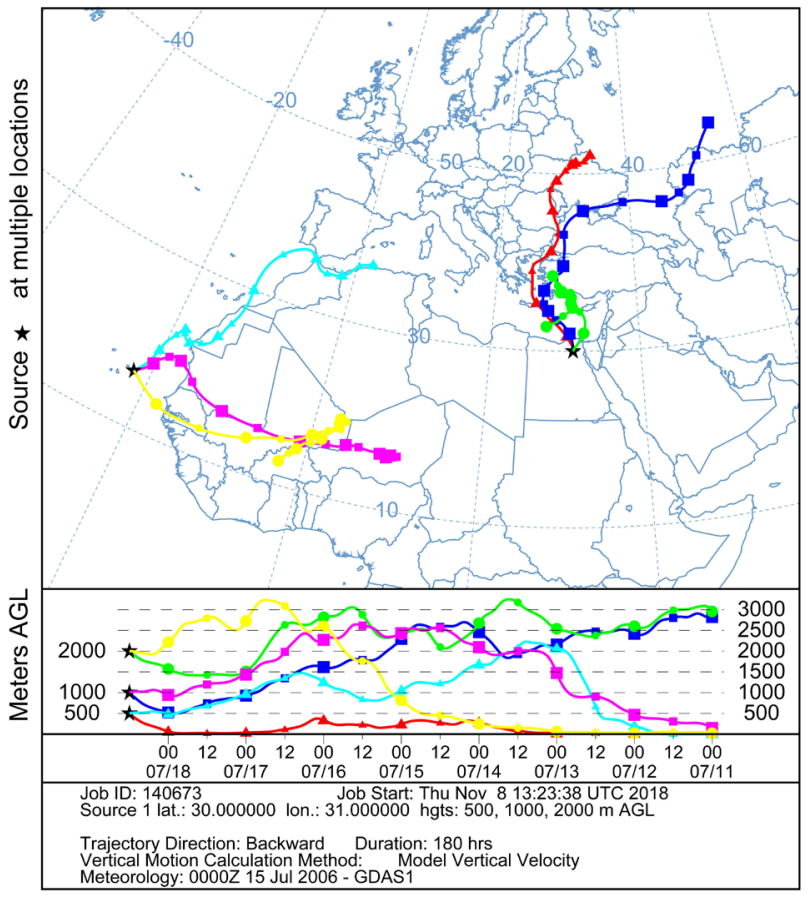

(e)

NOAA HYSPLIT MODEL

Backward trajectories ending at 1200 UTC 18 Oct 06

GDAS Meteorological Data

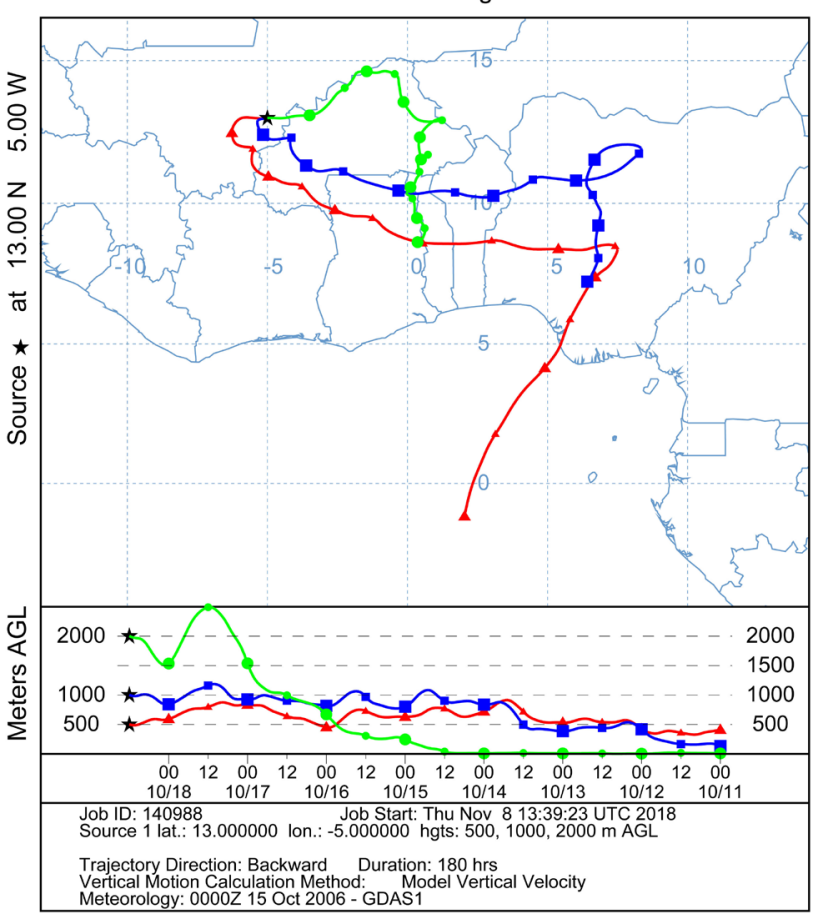

(f)

Figure 5. Seasonal representation of air masses seven day back trajectories plots showing the effect of pressure height and rainout in aerosol surface concentration in the region using NOAA HYSPLIT Model. 
DJF

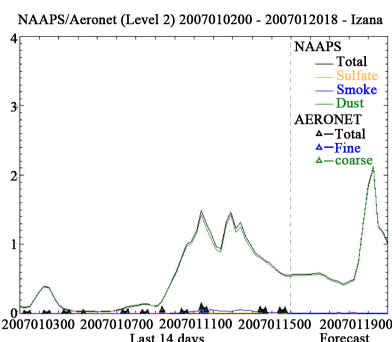

NAAPS/Aeronet (Level 2) 2007010200 - 2007012018 - Cape verd
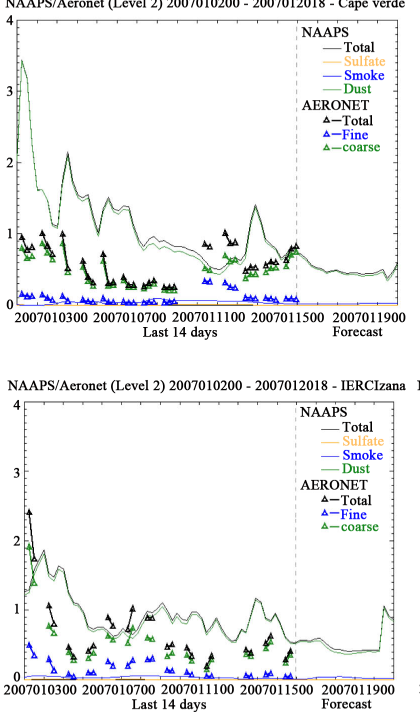

. NAAPS/Aeronet (Level 2) 2007010200 - 2007012018 - Ilorin

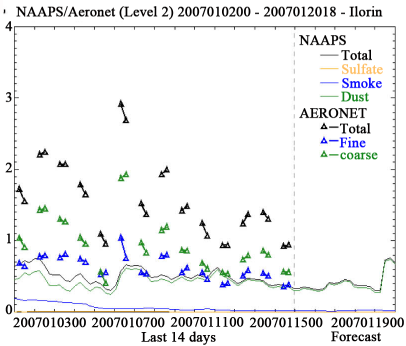

MAM
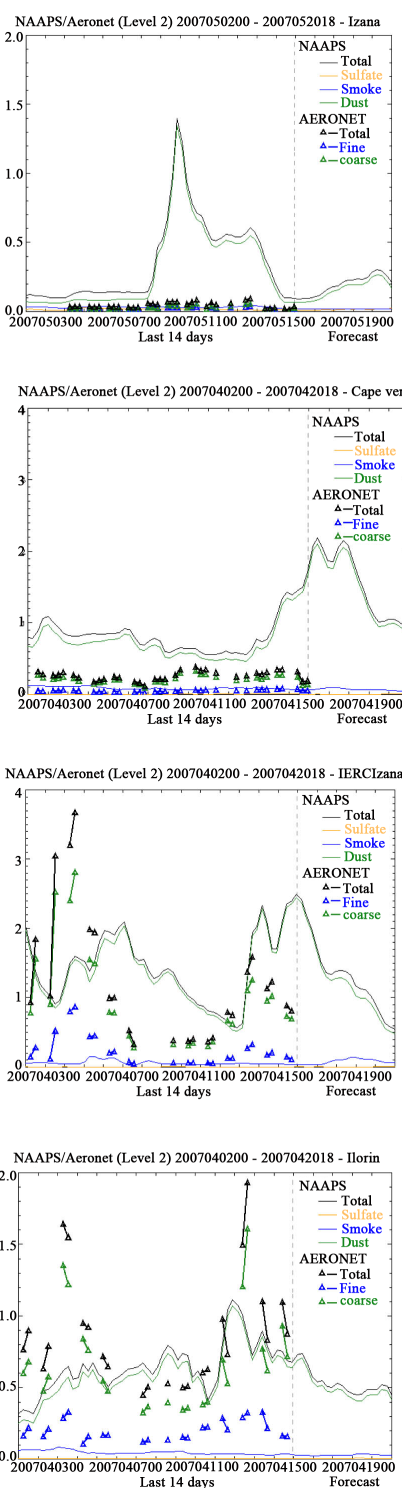

JJA

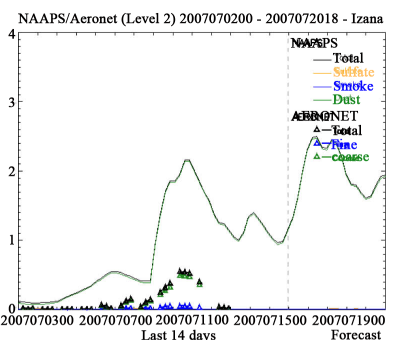

Last 14 days $\quad$ Forecas
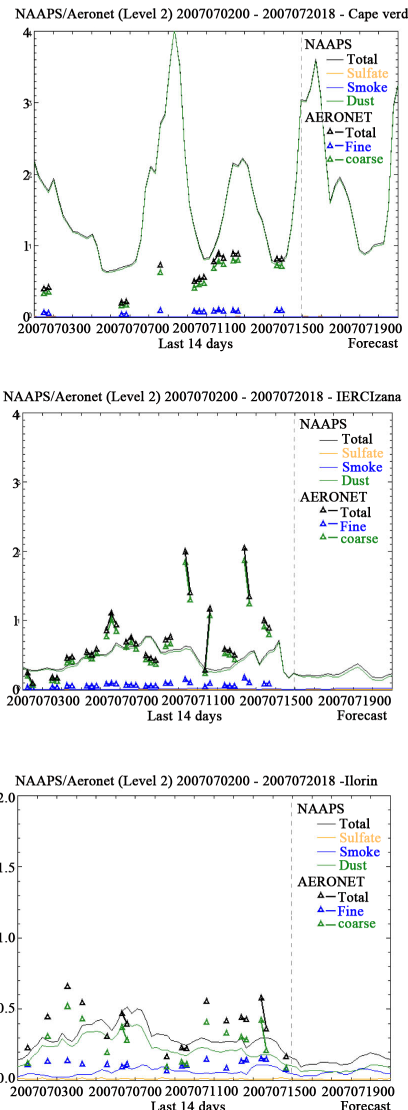

SON
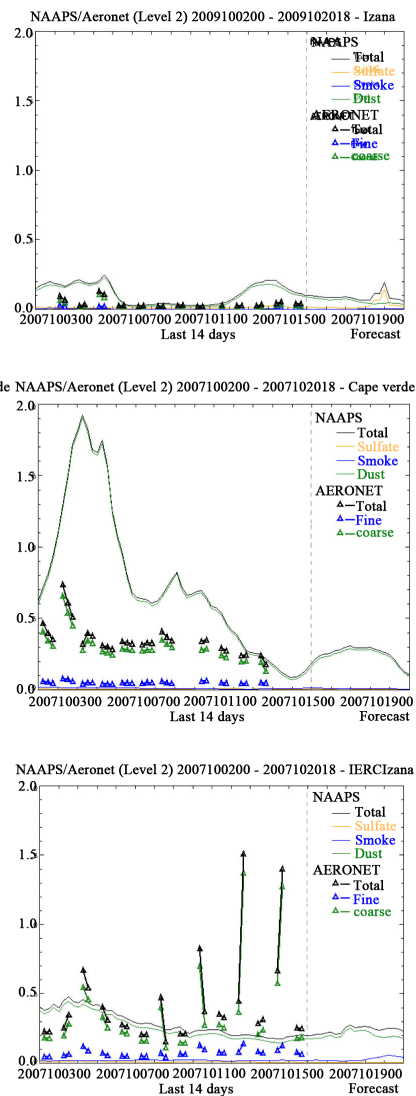

Figure 6. Seasonal comparative plot of NAAPS and AERONET AODs across the sites showing the temporal variation of magnitudes of AODs.

\& Cape verde) are good for studying long range transport due to their location been Islands and altitude, the sites is expected to receive mostly marine air masses and the potential influence of Sahara desert. The others sites (Cairo, Ilorin and Cinzana) are for investigating surface/local aerosol sources, due to their situation in the main land Africa with little foreign incursion. The seasonal representation (DJF, MAM, JJA, and SON) timelines of NAAPS 6-hour output and AERONET AOD measurements at various sites for 2007 are as shown in Figure 6 . In the plots, the black solid line represents $\tau_{N}$ in which all components are active, green line for dust, blue line for smoke, and yellow line for sulfate. The small triangular symbol represents the AERONET measurements with black color for $\tau_{A}$, green for coarse mode $\mathrm{AOD}\left(\tau_{C}\right)$ and blue for fine mode $\tau_{F}$. 
The comparison result shows that NAAPS prediction of $\tau_{N}$ is above $\tau_{A}$ across the season in the island stations and vice versa in the main land stations considered. The model predicts no influence of sulfate in most locations with the exception of a few instances at Izana in September to November; this means smoke is the major contributor to $\tau_{F}$ in the region. Dust prediction over the main land stations and the trend of $\tau_{C}$ observed by AERONET are always in the range $>1$ while a gap exist between them $\left(\tau_{N}>1, \tau_{A} \leq 1\right)$ in marine stations which may arise due to presence of sea spray and deposition/scavenging of Sahara dust during the transport [24]. The dominant particle size is coarse signifying amount of dust predicted by the model with little fine size particle in the far north sites while the down south sites have more percentage of smoke/fine mode $\tau$ than the far north sites. The rain out during the wet season reduces the population of aerosols present in the atmosphere leading to the reduction of magnitude of $\tau$ predicted and observed across board.

Furthermore, each site can be grouped into various dominant aerosol types based on the percentage population of composition shown in the comparison plots. Izana and Cape Verde are identified to be dust dominated sites while Cinzana and Ilorin are identified to be mixed sites of dust and smoke. Cairo NAAPS timelines were not reachable as at the time of compiling this report but using the spatial surface concentration map, it can be classified as a mixed site of dust and sulfate [25].

\section{Conclusion}

The long term AERONET dataset of aerosol optical depth is used to validate and evaluate the performance of combined MODIS AOD (Terra and Aqua) and NAAPS surface predictions in North Africa region. Over the region, the individual MODIS retrievals have some uncertainties due to complexities of nature of the surfaces ranging from bright in the deep Sahara to the partly/fully vegetated in the Sub-Sahel up to the coast of West Africa, which necessitate for the adoption of combined one. An examination of local aerosol sources and long range transport of the region was carried out by analysing the model simulation outputs and air masses trajectories using NOAA HYSPLIT. Statistical tools were employed to test the significant difference between the mean AOD of the three measurement methods. After filtering and matchups, the MODIS AODs of terra and aqua retrieved from the Land and Ocean algorithms are found highly correlated with AERONET $(\mathrm{R}>0.8)$ in the Sub-Sahel and averagely correlated $(\mathrm{R} \sim 0.7)$ in the Sahara. The retrieval over the remote island of Cape Verde is found to have highest agreement and no significant differences between the means with the AERONET with the least error of expectancy. Furthermore, the surface concentration predicted by NAAPS in the region was found to be correlated to measure AOD and the seasonal high aerosol loading is as a result of descending air masses and little wash out of the desert. It is generally observed that NAAPS overestimates the AOD in the Northern part of the study region 
and underestimates in the South. Also, the aerosol composition of the region is identified to be dust dominated in the North and mixed (dust and smoke) in the South. The results highlighted can be used to improve satellite retrieval algorithm in the region, serve as the input into global climate models, providing more accurate assessments of the aerosols' effects on climate change. It also presents aerosol sources into and from the region which may affect the level of air pollution in other regions of the world due to air-masses movement.

\section{Acknowledgements}

The Authors gratefully acknowledge the AERONET team and Principal Investigators of the sites (R. T. Pinker, J. L. Rajot, B. Marticorena, D. Tanri, E. C. Agullo, A. Zakey, B. Damiri) for the creation and maintenance of the Sun photometer data records. The MODIS Characterization Support Team is thanked for their extensive efforts in maintaining the high radiometric quality of MODIS data. NAAPS team is acknowledged for forecasting and keeping the NRL website running. We also thank our various institutions for the support rendered during the cause of this work.

\section{Conflicts of Interest}

The authors declare no conflicts of interest regarding the publication of this paper.

\section{References}

[1] Kaufman, Y.J., Tanré, D., Remer, L.A., Vermote, E.F., Chu, A. and Holben, B.N. (1997) Operational Remote Sensing of Tropospheric Aerosol over Land from EOS Moderate Resolution Imaging Spectroradiometer. Journal of Geophysical Research: Atmospheres, 102, 17051-17067. https://doi.org/10.1029/96JD03988

[2] Remer, L.A., et al. (2005) The MODIS Aerosol Algorithm, Products, and Validation. Journal of the Atmospheric Sciences, 62, 947-973. https://doi.org/10.1175/JAS3385.1

[3] Levy, R.C., et al. (2013) The Collection 6 MODIS Aerosol Products over Land and Ocean. Atmospheric Measurement Techniques, 6, 2989-3034. https://doi.org/10.5194/amt-6-2989-2013

[4] Shi, Y., et al. (2011) A Critical Examination of Spatial Biases between MODIS and MISR Aerosol Products-Application for Potential AERONET Deployment. At mospheric Measurement Techniques, 4, 2823-2836. https://doi.org/10.5194/amt-4-2823-2011

[5] de Gerrit, L., et al. (2011) The Remote Sensing of Tropospheric Composition from Space. Springer-Verlag, Heidelberg.

[6] Zhang, J., et al. (2011) Evaluating the Impact of Assimilating CALIOP-Derived Aerosol Extinction Profiles on a Global Mass Transport Model. Geophysical Research Letters, 38, 1-6. https://doi.org/10.1029/2011GL047737

[7] Johnson, K.C. (2006) A Comparison of the Navy Aerosol Analysis and Prediction System to In Situ Aerosol Measurements in the Continental U.S.: Transport vs. Local Production of Soil Dust Aerosol. Colorado State University, Fort Collins, CO. 
[8] Holben, B.N., et al. (2002) AERONET's Version 2. 0 Quality Assurance Criteria.

[9] Tanre, D., Kaufman, Y.J., Herman, M. and Mattoo, S. (1997) Remote Sensing of Aerosol Properties over Oceans Using the MODIS/EOS Spectral Radiances. Journal of Geophysical Research: Atmospheres, 102, 16971-16988. https://doi.org/10.1029/96JD03437

[10] Hsu, N.C., Tsay, S.C., King, M.D. and Herman, J.R. (2004) Aerosol Properties over Bright-Reflecting Source Regions. IEEE Transactions on Geoscience and Remote Sensing, 42, 557-569. https://doi.org/10.1109/TGRS.2004.824067

[11] Sayer, A.M., Hsu, N.C., Bettenhausen, C. and Jeong, M.-J. (2013) Validation and Uncertainty Estimates for MODIS Collection 6 "Deep Blue" Aerosol Data. Journal of Geophysical Research: Atmospheres, 118, 7864-7872.

https://doi.org/10.1002/jgrd.50600

[12] Hsu, N.C., Jeong, M.-J., et al. (2013) Enhanced Deep Blue Aerosol Retrieval Algorithm: The Second Generation. Journal of Geophysical Research: Atmospheres, 118, 9296-9315. https://doi.org/10.1002/jgrd.50712

[13] Westphal, D.L., et al. (2013) NAAPS Aerosol Analyses and Forecasts for Air Quality Applications. Naval Research Laboratory.

[14] Kinne, S., et al. (2003) Monthly Averages of Aerosol Properties: A Global Comparison among Models, Satellite Data, and AERONET Ground Data. Journal of Geophysical Research: Atmospheres, 108, 1-42. https://doi.org/10.1029/2001JD001253

[15] Smirnov, A., Holben, B.N., Eck, T.F., Dubovik, O. and Slutsker, I. (2000) Cloud-Screening and Quality Control Algorithms for the AERONET Database. Remote Sensing of Environment, 73, 337-349.

[16] Ångström, A. (1964) The Parameters of Atmospheric Turbidity. Tellus, 16, 64-75. https://doi.org/10.3402/tellusa.v16i1.8885

[17] Willmott, C.J. (1984) On the Evaluation of Model Performance in Physical Geography. In: Gaile, G.L. and Willmott, C.J., Eds., Spatial Statistics and Models. Theory and Decision Library (An International Series in the Philosophy and Methodology of the Social and Behavioral Sciences), Springer, Dordrecht, 443-460. https://doi.org/10.1007/978-94-017-3048-8_23

[18] Rolph, G., Stein, A. and Stunder, B. (2017) Real-Time Environmental Applications and Display System: READY. Environmental Modelling \& Software, 95, 210-228.

[19] Aeronet, T. (2006) AERONET Inversion Products. NASA, Greenbelt, MD.

[20] Schuster, G.L. and Dubovik, O. (2002) Use of AERONET Aerosol Retrievals to Calculate Clear-Sky Irradiance at the Surface. Science, 1-6.

[21] Seidel, F.C. and Popp, C. (2012) Critical Surface Albedo and Its Implications to Aerosol Remote Sensing. Atmospheric Measurement Techniques, 5, 1653-1665. https://doi.org/10.5194/amt-5-1653-2012

[22] Anderson, J., Wang, J., Zeng, J., Petrenko, M., Leptoukh, G.G. and Ichoku, C. (2012) Accuracy Assessment of Aqua-MODIS Aerosol Optical Depth over Coastal Regions: Importance of Quality Flag and Sea Surface Wind Speed. Atmospheric Measurement Techniques Discussions, 5, 5205-5243. https://doi.org/10.5194/amtd-5-5205-2012

[23] Di Tomaso, E., Schutgens, N.A.J., Jorba, O. and García-Pando, C.P. (2017) Assimilation of MODIS Dark Target and Deep Blue Observations in the Dust Aerosol Component of NMMB-MONARCH Version 1.0. Geoscientific Model Development, 10, 1107-1129. https://doi.org/10.5194/gmd-10-1107-2017 
[24] David, R.R. (2005) Aerosol Optical Properties and Particle Size Distributions on the East Coast of the United States as Derived from Airborne in Situ and MISR Remote Sensing Measurements. University of Washington.

[25] Bergstrom, R.W., et al. (2007) Spectral Absorption Properties of Atmospheric Aerosols. Atmospheric Chemistry and Physics, 7, 5937-5943.

https://doi.org/10.5194/acp-7-5937-2007 